\title{
In Memoriam: Professor Fumio Matsuura (1915-2013)
}

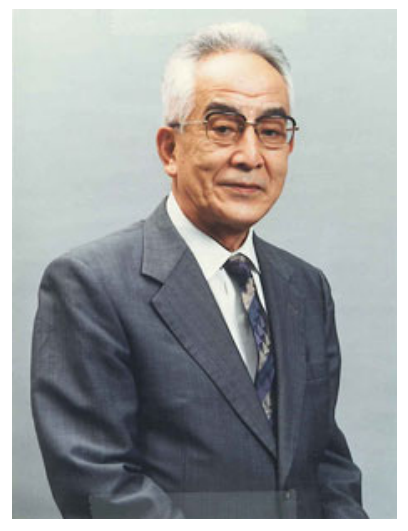

Professor Fumio Matsuura, an Honorary Member of the Japanese Society of Fisheries Science and a Professor Emeritus of the University of Tokyo and Kitasato University, passed away on 10 March 2013. He was 97 years old.

Professor Matsuura was born on 20 March 1915 in Tokyo. After graduating from the Department of Fisheries, Faculty of Agriculture, Tokyo Imperial University in March, 1939, he was assigned as an officer in the Ministry of Agriculture and Forestry of Japan. In 1941, he assumed the position of Lecturer in Tokyo Imperial University, from which he had graduated. After serving as Associate Professor, he assumed the position of Professor in 1956. After fulfilling several significant university positions, including councilor of the faculty, he retired from the University of Tokyo in March, 1979, and was conferred the honor of Professor Emeritus. Following his retirement, he assumed the position of Professor and Dean in the School of Fisheries Sciences, Kitasato University. From 1981 to 1985, he assumed the president of Kitasato University. There, Professor Matsuura, contributed to the development of Kitasato University with his deep academic knowledge, superior intellect, and noble personage. In 1985, he was conferred the honor of Professor Emeritus from Kitasato University.

Professor Matsuura's work covered a wide range of marine biochemistry. He studied the characteristic biochemical nature of aquatic animal proteins. What is notable is a series of studies on fish hemoproteins such as fish myoglobin and hemoglobin. He isolated these proteins from fishes for the first time and showed the remarkable difference in the biochemical characteristics between fish and mammals. Above all, the finding of multiple hemoglobins of fish with different physiological activities is highly valued worldwide. He received the Japanese Society of Fisheries Science Award of Merit from a series of studies done in 1971.

Professor Matsuura also made extensive contributions to the Japanese Society of Fisheries Science, serving most notably as a member of the Board of Directors, and finally as President. He also served tirelessly on various committees essential to running the affairs of the Society, and headed one of the Society's biannual meetings. He also served on many advisory committees under the Ministry of Education, Science, Sport and Culture, and the Ministry of Agriculture, Forestry and Fisheries, thus, helping to bridge academia and the bureaucracy. In recognition of his invaluable contributions to education and research, government and society, he was awarded the Third Order of Merit with Semi-Grand Cordon of the Rising Sun in 1988 .

Professor Matsuura educated and inspired many young people with his wide-ranging intellect and warm personality. His legacy will always be remembered with fond memories of bygone days.

Masaaki Kodama

Professor Emeritus Kitasato University 